\title{
The Counselling Self-Estimate Inventory (COSE): Does it work in Chinese counsellors?
}

\author{
MANTAK YUEN \\ University of Hong Kong, China
}

\section{RAYMOND CHAN}

Hong Kong Baptist University, China

\section{PATRICK LAU MAN-PING LAM DANIEL T.L. SHEK \\ Chinese University of Hong Kong, China}

Submitted to: Counselling Psychology Quarterly; April 302003

Accepted for publication: Dec 22003

\section{Acknowledgement}

The article is based on Mantak Yuen's PhD thesis completed under the supervision of Man-ping Lam and Daniel T. L. Shek at the Chinese University of Hong Kong. The research is financially supported by the Committee for Research and Conference Grants of the University of Hong Kong.

About the authors

Mantak Yuen is an assistant professor in the Faculty of Education, The University of Hong Kong. Raymond Chan is an assistant professor in the Department of Educational Studies, Hong Kong Baptist University. Patrick Lau is an associate professor in the Department of Educational Psychology, The Chinese University of Hong Kong.

Man-ping Lam is a professor in the Department of Educational Psychology, The Chinese University of Hong Kong. Daniel T.L. Shek is a professor in the Department of Social Work, The Chinese University of Hong Kong.

Correspondence to: Mantak Yuen, Faculty of Education, the University of Hong Kong. Pokfulam, Hong Kong, China (e-mail: mtyuen@hkucc.hku.hk). 


\title{
The Counselling Self-Estimate Inventory (COSE): Does it work in Chinese counsellors?
}

\begin{abstract}
Counselling self-efficacy is an important construct for research and evaluation in counsellors’ competencies and training effectiveness. Larson, Suzuki, Gilliespie, Potenza, Bechtel, \& Toulouse (1992) developed the Counselling Self-Estimate Inventory (COSE) for counsellors in America and examined its factor structure using exploratory factor analysis. They recommended a five-factor model (Microskills, Counselling Process, Difficult Client behaviour, Cultural Competence, and Awareness of Values) and the use of the COSE for future research. However, little research has investigated the validity of the COSE in the context of counselling Chinese students in schools. In the present study, the factor structure of responses to the Chinese version of the Counselling Self-Estimate Inventory in a sample of 578 Hong Kong secondary school guidance teachers was examined using the EQS approach to confirmatory factor analysis. The results showed that while a five-factor model was fairly able to fit the data, the deletion of items related to the Awareness of Values factor yielded a better fitting model. The discussion of potential uses and limitations of the C-COSE in the context of preparing and supervising school guidance personnel in student counselling is relevant to counselling psychologists and researchers in Hong Kong and other parts of the world.
\end{abstract} Key words: Counselling self-efficacy; Hong Kong Chinese; Guidance Teachers 


\section{The Counselling Self-Estimate Inventory (COSE): Does it work in Chinese counsellors?}

\section{Introduction}

In recent years, the construct of counselling self-efficacy has gained much attention among counsellor educators and researchers (e.g. Johnson, Baker, Kopala, Kiselica, \& Thompson III, 1989; Larson \& Daniels, 1998; Lent, Hill, \& Hoffman, 2003; Sharpley, \& Ridgway, 1993). Larson and Daniels (1998) have defined counselling self-efficacy as an individual's “beliefs about one's capabilities to effectively counsel a client in the near future” (p. 180). Most researchers have examined counselling self-efficacy and their correlates in samples of counsellor-trainees and professionally trained counsellors. They have found that counsellors' anxiety and performance, and supervision environment are related to counselling self-efficacy. It has been found that counselling self-efficacy affects how far counsellor trainees will persist and the level of anxiety they experience before practicum and in practicum and supervision (Friedlander, Keller, Peca-Baker, \& Olk, 1986; Johnson, Baker, Koala, Kiselica, \& Thomspon, 1989; Larson et al., 1992; Sharpley \& Ridgway, 1993).

\section{Counselling self-efficacy measures}

A review of the literature by Larson \& Daniels (1998) found that there were 10 
measures of counselling self-efficacy in published studies. Four of them were on individual counselling microskills. They were the Interpersonal Skills Efficacy Scale (ISES; Munson, Zoerink, \& Stadulis, 1986), Counsellor Behavior Evaluation-Self-Efficacy (CBE-SE; Munson, Stadulis, \& Munson, 1986), the Counsellor Self-Efficacy Scale (CSES; Johnson et al., 1989), and the Counselling Self-Estimate Inventory (COSE; Larson et al., 1992). Two measures included group counselling (the Counsellor Self-Efficacy Scale; COSES; Melchert, Hays, Wiljanen, \& Kolocek, 1996) and counsellors' other domains of work, such as case management, family interventions, and assessment (the Self-Efficacy Inventory; S-EI; Friedlander \& Snyder, 1983). There was also the Counsellor Self-Efficacy Survey (CSS; Sutton \& Fall, 1995) for school counsellors; the Career Counselling Self-Efficacy Scale (CSES; O’Brien, Heppner, Flores, \& Bikos, 1997) for career counsellors, the Self-Efficacy Questionnaire (S-EQ; Margolies, Wachtel, \& Schmelkin, 1986) for psychiatrists, and the Self-Efficacy Item (SEI; Sipps, Sugden, \& Faiver, 1988) as a process assessment tool for categories of counsellor responses. Few empirical data were found on the validity of the measures, except for the COSE, the CSS, and the CSES (Larson \& Daniels, 1998).

The Counselling Self-Estimate Inventory (COSE)

Among the various counselling self-efficacy measures, the psychometric 
properties of the COSE have been mostly well studied and reported by researchers. Larson et al. (1992) developed the COSE for use in training, supervision, and research relating to the development of self-efficacy in counselling among counsellor trainees. Sixty-seven items were specifically written to include both positive and negative statements about counselling self-efficacy. Respondents were asked to rate on a 6-point Likert scale from 1 (strongly disagree) to 6 (strongly agree) to indicate how they would perform in a counselling situation at the present time. There were 213 counsellor trainees from three master's programmes at different universities who were asked to complete the inventory along with a number of other well-established instruments at the end of the semester. Factor analysis indicated that Counsellor Self-Efficacy was a multidimensional construct. The COSE was further reduced to 37 items with five underlying factors: Microskills, Counselling Process, Difficult Client Behaviour, Cultural Competence, and Awareness of Values. Correlation analyses were conducted between the COSE total and five-factor scores and criterion measures. It was found that counsellor trainees who reported higher counselling self-efficacy also reported higher self-conception scores, less state and trait anxiety, and higher effectiveness in problem solving. In addition, the correlations between the COSE total and five-factor scores and the Social Desirability Scale score were weak. In another study of 213 counsellor trainees, 52 master’s level counsellors, and 56 counselling psychologists, it was found 
that the counsellor trainees had significantly lower counselling self-efficacy scores than both the master's level counsellors and the counselling psychologists. In another study of 26 graduate students, it was found that the STAI Trait Anxiety scale and the COSE total scores were significant predictors of the graduate students' performance in a mock interview as rated by two independent raters. The multidimensional COSE was useful in research and counsellors' training and supervision (Larson \& Daniels, 1998). However, a further survey of the literature showed that the COSE's validity and reliabilities were initially only established in the US samples. None of the research in the literature provided empirical verification of the factor structure nor tested the higher-order model using confirmatory factor analyses nor in samples of less well trained guidance personnel, specifically, school teachers with additional student counselling and guidance duties.

A Case for the Chinese Version of the COSE

In Hong Kong, through the implementation of a whole school approach to guidance, there are increasing opportunities for teachers to be involved in counselling and guidance (Gysbers, 2000; Hui, 2000; Watkins, 2001;Yuen, Lam \& Shek, 2001). In secondary schools, the guidance teacher model has been around since 1986 and has 
become widely established. The guidance teachers, who are full-time teachers, are given the duties of managing and developing the general guidance programmes and providing counselling and guidance to students in school. With guidance on top of their teaching duties, they are often involved in guiding students who have behavioural, emotional and learning difficulties (Hong Kong Education Department, 1986; 2001). Although guidance is regarded as an essential part of a teacher's role, many teachers do not appear to have had any training in counselling and guidance during their teacher-education programmes. To compensate for this inadequacy in counselling and guidance training, short courses and seminars are run for guidance teachers by the Education Department (Hong Kong Education Department, 2000). Tertiary institutions also run four one-year part-time certificate programmes for secondary school guidance teachers. About $58 \%$ of the guidance team leaders and $20 \%$ of the guidance team members have been trained at certificate level (Luk Fong \& Lung, 1999). However, there has been a lack of assessment instrument for measuring guidance teachers' self-reported estimate of their counselling competencies in counselling training and programme evaluation.

In addition, the development and validation of the Chinese version of the COSE would be a significant step forward in understanding the applicability of the Western construct of Counselling Self-Efficacy to Asian contexts (Shek, 1999). The construct of 
Counselling Self-Efficacy, when it was first developed, was supposed to be free from any particular counselling theory and included mainly generic counselling competencies in graduate level programmes in the United States (Larson et al., 1992). The construct of Counselling Self-Efficacy could be universal rather than culturally specific, as Patterson (1996) pointed out that respect for the client, genuineness, empathic understanding, communication of empathy, respect, and genuineness, and structuring are five basic counsellor qualities and competencies. Furthermore, the exploration and measurement of Hong Kong guidance teachers' school counselling efficacy beliefs would be an important step in understanding Chinese teachers' behaviour in the domain of counselling and guidance. As Pedersen (1996) asserted: “Counsellors need to acknowledge that the functions of counselling have been alive and healthy as long as civilizations have existed, even though the labels we use are relatively recent” (p.236).

The data reported in this paper were based on a study primarily designed to investigate the relationships among secondary guidance teachers' efficacy beliefs, training level, and burnout, with the C-COSE as one of the survey instruments. The present paper reports only the factorial structure and reliability of the C-COSE. Data related to Hong Kong guidance teachers’ positive beliefs, counselling involvement, training needs, attitudes towards students’ special needs, teaching efficacy and burnout 
have been reported elsewhere (Yuen, in press; Yuen, Lam, \& Shek, 2001; Yuen, Lau, Shek, \& Lam, 2002; Yuen, Shek, Lam, Lau, \& Chan, in press; Yuen \& Westwood, 2001; 2002).

\section{Method}

To test whether the 37 items of C-COSE adequately represent the five-factor model of counselling self-efficacy as proposed by Larson et al. (1992), a series of three models were constructed.

Model 1. An Omnibus General Counselling Self-Efficacy Factor.

This model postulates that all 37 items of the C-COSE reflect an omnibus common factor in which all of these items are equally indicative of general counselling self-efficacy with no extraneous correlation among the items due to unspecified factors.

Model 2. Five Distinguishable Factors: Microskills, Process, Difficult Client Behaviour, Cultural Competence, and Awareness of Values.

Based on previous research (Larson et al., 1992) in the exploratory factor analysis, the findings indicate that five factors can be extracted from the C-COSE scale. It was hypothesized that five specific factors are distinguishable: Microskills (1, 3, 4, 5, 8, 10 , 
11, 12, 14, 17, 32, 34), Process (6, 9, 16, 18, 19, 21, 22, 23, 31, 33), Dealing with Difficult Client Behaviour (15, 20, 24, 25, 26, 27, 28), Cultural Competence (29, 30, 36, $37)$, and Values $(2,7,13,35)$.

Model 3. Null Model

The C-COSE items were specified to be unrelated, and no common factor was hypothesized to underlie them.

\section{Goodness-of-Fit Indices}

Based on statistical grounds and suggestions by previous researchers, the indices employed in this study included the chi-square value (Wheaton, 1987), the chi-square / degrees of freedom ratio (Wheaton, 1987), the Bentler-Bonett nonnormal fit index (NNFI; Bentler, 1989), the comparative fit index (CFI; Bentler, 1989), the goodness-of-fit index (GFI; Joreskog \& Sorbom, 1985), the adjusted goodness-of-fit index (AGFI; Joreskog \& Sorbom, 1985), the root mean square residual (RMSR; MacCallum, Browne, \& Sugawara, 1996; Steiger \& Lind, 1980), and the root mean square error of approximation (RMSEA; Browne \& Cudeck, 1993; MacCallum et al., 1996). The root mean square residual and the root mean square error of approximation are given higher priority to other indices as they are recommended as the most 
straightforward and intuitive approach to understanding the fit of a model (Quintana \& Maxwell, 1999).

The Hypothesis

It was hypothesized that if five latent variables underlying the response to the

C-COSE items are subsumed under a 5 dimensional factor construct of counselling self-efficacy, Model 2 would yield a more parsimonious fit to the data than would Model 1. In addition, the desirability of Model 2 would be assessed in terms of its convergent validity (i.e. the extent to which the specified items converge on a particular factor in terms of the magnitude of the item loadings)

\section{Participants}

Participants in this study were 578 guidance teachers who were full-time secondary teachers with additional duties of managing the school guidance programme, and providing counselling and guidance services to students. Questionnaires were sent to 98 secondary schools for the guidance team leader and four guidance team members to complete. Eighty-three schools responded and returned 338 valid questionnaires (a response rate of $68.6 \%$ ). In addition, another 240 valid questionnaires were collected from the guidance team leaders who responded to a questionnaire sent to their 
respective schools (a response rate of $69.97 \%$ ). Table I shows $54.5 \%$ of the participants were guidance team leaders and $45.5 \%$ were guidance team members (396 women and 167 men). Fifteen participants did not indicate their sex. 54\% of the participants received systematic counselling training at certificate or master’s levels.

Insert TABLE I about here

\section{Instrumentation}

Counseling Self-Estimate Inventory (COSE). The 37-item COSE was developed by Larson et al. (1992) in an attempt to assess a counsellor trainee’s confidence in using microskills, attending to processes, dealing with difficult client behaviour, behaving in a culturally competent way, and being aware of his or her values. The total scale and subscales showed acceptable reliability coefficients. They were used in a number of research and evaluation studies related to counsellor training (Larson \& Daniels, 1998). Thus, the 37-item Counselling Self-Estimate Inventory (Larson et al., 1992) was translated into Chinese by the principal researcher with the kind permission of Lisa Larson, and was then translated back into English by an independent translator to ensure accuracy of meaning. The term fu dao was used and was specified in the 
instruction as equivalent to the English term individual counselling. Where clarity was questioned, items were modified. The draft questionnaire was then piloted on a group of in-service teachers taking a postgraduate education course in a university ( $\mathrm{n}=12$ ). Based on the feedback from this pilot administration the wording of some items was further refined for clarity.

The questionnaire required each respondent to register his or her level of agreement with each statement. A 6-point, Likert scale was provided for each item, with 1 representing strongly disagree, 2 disagree, 3 slightly disagree, 4 slightly agree, 5 agree, and 6 strongly agree.

\section{Results}

The models on the factor structure of the C-COSE were tested by the EQS confirmatory factor analysis approach (Bentler, 1995; Bentler \& Wu, 1995). The identical confirmatory factor analyses were carried in the total sample and three sub-samples. Sub-sample 1 comprised guidance teachers who had no training in counselling ( $n=66$ ). Sub-sample 2 were guidance teachers who had about 15 to 60 hours of training in counselling $(n=141)$. Sub-sample 3 were guidance teachers with certificate or master's level of training in counselling $(n=312)$. The goodness-of-fit indicators for Models 1 to 3 are summarized in Table II. Across several indices, it appeared that the five-factor model (Model 2) was the best fit compared with the 
competing models, primarily because it had the following lowest statistics (e.g. for the total sample, $X^{2}=2125.228$, RMSR $=.073$, and RMSEA $=.068$; for the certificate/master's level sample, $\mathrm{X}^{2}=1445.530$, $\mathrm{RMSR}=.076$, and RMSEA $=.068$ ). For the total sample and the certificate/master's level sample, though their NNFI and CFI were slightly lower than the normally expected level of .90 (Bentler, 1995; Byrne, 1994), their RMSR and RMSEA indicated a fair fit of data (Kline, 1998; MacCallum et al., 1996; Quintana \& Maxwell, 1999). For the sample of guidance teachers without counselling training and that of guidance teachers with 15 to 60 hour training, the findings did not indicate a satisfactory fit of data.

Insert TABLE II about here

Further examination of the structure coefficients for the items of the C-COSE showed that most of the items converged with relevance on the respective factors hypothesized in this model. Table III summarizes findings of the total sample and the sample of guidance teachers with certificate/master's training. For the Microskills factor, all out of the 12 items had loadings higher than .50. For the Process factor, all 10 
items had loadings higher than .50. For Handling Difficult Client Behaviour, 6 out of 7 items had loadings higher than .40. For the Cultural Competence factor, the 4 items had loadings ranging from .32 to .82 . For the Awareness of Values factor, 2 out of 4 items had loadings lower than .30 (items $2 \& 7$ ).

The correlations among the factors are shown in Table IV. The factors of Microskills, Process, Difficult Clients, and Cultural Competencies were moderately correlated, while the Awareness of Values factor correlated mildly with the other factors.

Insert TABLE III about here

Insert TABLE IV about here

The internal consistencies of the Microskills, Process, Difficult Client Behaviour, and Cultural Competence factors were adequate (alphas ranged from .62 to .92). The internal consistency of the total scale was adequate (alpha $=.94)$. However, the internal consistency of the Awareness of Value factor (alpha $=.14$ ) was not satisfactory. 
Post hoc confirmatory factor analysis

Since the Awareness of Value factor showed low internal consistencies, four items of the subscale (nos. 2, 7, 13, 35) were deleted from the C-COSE; a four-factor model (Model 5) was formulated by deleting these four items from Model 2. Goodness of fit statistics related to this model are shown in Table V. To further cross-validate the results of the initial analysis, the sample statistical procedures were conducted among three sub-samples. Sub-sample 1 comprised guidance teachers who had no training in counselling $(n=66)$. Sub-sample 2 were guidance teachers who had 15 to 60 hours training in counselling $(n=141)$. Sub-sample 3 were guidance teachers who had certificate or master level training in counselling $(n=312)$. Table II and Table V show that for the total sample and the three sub-samples, across several indices, it appeared that Model 5 (four-factor model with items 2, 7, 13, \& 35 deleted) was the best fit compared with the competing models, primarily because it had the following lowest statistics: total sample, $\mathrm{X}^{2}=8565.599, \mathrm{RMSR}=.067$, and RMSEA $=.070$; sub-sample $1, \mathrm{X}^{2}=899.465, \mathrm{RMSR}=.087$, and RMSEA $=.120$; sub-sample $2, \mathrm{X}^{2}=922.361, \mathrm{RMSR}$ $=.084$, and RMSEA $=.083$; sub-sample $3, \mathrm{X}^{2}=1195.310$, RMSR $=.065$, and RMSEA $=.071$ ). For the whole sample and sub-sample 3, though their its NNFI and CFI were lower than .90, the level one would normally expect (Bentler, 1995; Bryne, 1994), their 
RMSR and RMSEA indicated a fair fit of data; for sub-sample 2, their RMSR and RMSEA indicated a mediocre fit of data; for sub-sample 1, their RMSR and RMSEA did not indicate a satisfactory fit to the data (Kline, 1998; MacCallum et al., 1996; Quintana \& Maxwell, 1999). Table V shows the factor loadings of the revised C-COSE for the total sample and the three sub-samples. For the total sample, the factor loadings for the Mircoskills ranged from .58 to .79.; for the Process from .59 to .83; for the Difficult Clients Behaviour from .36 to .74; and for the Cultural Competencies from .33 to .80 . The results indicated that factor structures for the sub-samples $2 \& 3$ resembled closely those of the total sample.

\section{Insert TABLE V about here}

Inter-correlations and reliabilities of the revised C-COSE

The inter-correlations, means, standard deviations, and reliabilities (alpha) of the subscales scores are reported in Table VI. The results show that the scores of Microskills, Process, Difficult Client Behaviour, and Cultural Competencies Subscales were moderately correlated in the sub-samples ( $r$ ranged from .23 to .69). The internal consistencies of the Microskills, Process, Difficult Client Behaviour, and Cultural 
Competencies Subscales were adequate (sub-sample 1, alphas $=.94, .82$ and .76; sub-sample 2, alphas $=.89, .90$ and .74 ; and sub-sample 3, alphas $=.92, .91$ and .81 ). The internal consistency for the Cultural Competencies Sub-scale was barely satisfactory (sub-sample alphas $=.57, .56$ and .63 ).

Insert TABLE VI about here

Discussion

The study demonstrated the usefulness of confirmatory factor analysis in validating the factorial structure of assessment instruments cross-culturally (Cole, 1987; Shek, 1993; Watkins, 1989). However, several limitations of this study must be acknowledged.

Here a Western instrument, the Counselling Self-Estimate Inventory (COSE), was translated and validated through the etic approach. While confirmatory factor analysis of the participants' responses offered support for the five-factor structure of the C-COSE (Larson et al., 1992), the four-factor structure of the revised C-COSE provided a better fit to the data. The Microskills, Process, Difficult Client Behaviour and Cultural Competencies Subscales demonstrated acceptable internal consistency. 
However, the Awareness of Value subscale showed low reliability. This may be due to the possible ambiguity in these subscale items (e.g. items 2 and 7) for guidance teachers in Hong Kong, the contextual differences in values between Hong Kong guidance teachers and American counsellors, and the tapping of values construct rather than self-efficacy in the items of the Awareness of Values subscale (Lent, Hackett, \& Brown, 1998; Lent, Hill, \& Hoffman, 2003). For example, the negative item total correlation of items 13 and 35 indicated that guidance teachers with inadequate training might possibly consider the value issue from different and opposing perspectives from those presumed in the COSE.

In addition, the mean score of item 35 “I feel I may give advice” (reverse coded; M $=2.23$; S.D. $=.63$ ) indicated the guidance teachers had high confidence in their capability in giving advice to students. In the multi-cultural counselling literature, it has been considered that some Chinese clients might experience conflicting values, particularly in their relationships with parents and teachers (Kwan, 2000). Following the Confucian ideal of filial piety, some guidance teachers might expect students to obey external school rules rather than follow their own internal values and goals, and confront students' values rather than respect their choices (Ho, 1996). In the school counselling literature, research studies have suggested guidance teachers may experience role conflict and ambiguity (Agee, 2003; Miller, Manthel, \& Gilmore, 1993). 
This has significant implications for preparation and supervision of guidance personnel in their role of counselling students. Guidance personnel needed to be better prepared and supervised in their awareness of values issues in counselling (Lau, 2000). Counselling psychologists could be involved in the supervision, personal development and continued professional development of the school guidance personnel (Farrell, 1996).

The mean scores of subscales indicated that the guidance teachers had confidence in using microskills in counselling (sub-sample Microskills Subscale item means $=4.24,4.48$, and 4,69), while they tended to be less confident in their capabilities in handling difficult client behaviour (sub-sample Difficult Client Behaviour item means $=3.24,3.53$, and 3.79). The data also suggested that counselling training might help guidance teachers develop self-efficacy in their capabilities in counselling students. A longitudinal experimental design evaluation study would be necessary to provide empirical evidence showing the effects of counselling training programmes on trainees’ counselling self-efficacy.

Another limitation is that the present sample consisted only of secondary school guidance teachers who responded to the survey questionnaires. In future research, it would be interesting to cross-validate the C-COSE in various samples of guidance personnel (e.g. full-time primary school guidance teachers and counselors, full-time 
school social workers, and guidance teachers in in-service counseling training program) in different Chinese societies. Ideally, structural invariance evidence has to be obtained before the C-COSE is used to compared self-efficacy in different groups (e.g.male or female groups). Further validation studies should aim to investigate the concurrent, construct and predictive validity of the scale.

Lastly, another limitation of the study was its reliance on self-reporting. Chinese people might tend to be modest in reporting their self-efficacy. Modesty is a Confucian virtue characterized by not speaking too highly of one’s competencies. One tends to express a lower level of confidence in public than one really feels in private. Further studies might also be conducted to provide independent verification of the extent of the sense of self-efficacy and investigate its relation to actual effective performance of the guidance teachers.

In sum, we would like to recommend that the four subscale scores of the revised C-COSE be adopted as useful indicators of the confidence in using microskills, process skills, handling difficult client behaviour, and cultural competencies in individual counselling self-efficacy among guidance teachers in Hong Kong. On the other hand, items of the Awareness of Values subscale needs to be further modified to fit the Chinese student counselling context. The C-COSE would be useful for counselling professionals, educators and researchers in Chinese communities to assess guidance 
personnel's level of confidence in using microskills, process, handling difficult client behaviour and cultural different clients. Potential uses of the C-COSE include the assessment of guidance personnel's self-efficacy in individual counselling, and the evaluation of changes in trainees' efficacy beliefs in counselling training programmes.

The C-COSE could be used to monitor changes in guidance personnel's efficacy beliefs in the implementation process of innovations such as comprehensive guidance programme (Yuen \& Westwood, 2001; Yuen, Lau, \& Chan, 2000). The C-COSE could also be used as a feedback device for participants in counselling training programmes. Programme participants could further share among themselves about their beliefs in using microskills, directing the counselling process, handling difficult client behaviour, cultural diversity, and value issues (Clarkson \& Nippoda, 1998; .Shillito-Clarke, 1996).

Regarding the school guidance personnel's crucial diversified roles in delivering a comprehensive school developmental guidance programme (Bor, Ebner, Gill, \& Brace, 2002; Gysbers \& Henderson, 2000; Hong Kong Education Department, 1995; 2001; Hui, 1994; Lairio \& Nissilae, 2002; Schmidt, 1997; Watkins, 2001) as well as the narrow focus on individual counselling of the C-COSE, there is an obvious need for an indigenous instrument specifically designed to measure school counselling and guidance self-efficacy, particularly in the various aspects of counselling and guidance 
work, for the Hong Kong Chinese school context. In addition, if the instrument was to be used in school guidance personnel preparation and supervision, it should be based on a sound theory-based training model of school counselling (Gysbers, 2000; Hornby, 2003; Lent, Hill, Hoffman, 2003). 


\section{References}

AGEE, M. .A. (2003). Ethical issues in counseling for teachers. In G. HORNBY, C. HALL, \& E. HALL (Eds.), Counselling pupils in schools: Skills and strategies for teachers. London: RoutledgeFalmer.

BENTLER, P. M. (1989). EQS structural equations program manual. Encino, CA: Multivariate Software Inc.

BENTLER, P. M. (1995). EQS structural equations program manual. Encino, CA: Multivariate Software Inc.

BENTLER, P. M., \& WU, E.J.C. (1995). EQS for Windows user's guide. Encino, CA: Multivariate Software Inc.

BOR, R., EBNER, L.J., GILL, S., \& BRACE, C. (2002). Counselling in schools. Thousand Oaks, CA: Sage.

BROWNE, M.W., \& CUDECK, R. (1993). Alternative ways of assessing model fit. In K.A. BOLLEN \& J.S. LONG (Eds.), Testing structural equations models (pp.136-162). Newbury Park, CA: Sage.

BYRNE, B.M. (1994). Structural equation modeling with EQS and EQS/Windows. Thousand Oaks, CA: SAGE

CLARKSON, P. \& NIPPODA, Y. (1998). Cross-cultural issues in counselling psychology practice: a qualitative study of one multicultural training 
organization. In P. CLARKSON, (ed.). Counselling psychology: Integrating theory, research and supervision practice. pp. 95-118. London: Routledge.

COLE, D. A. (1987). Utility of confirmatory factor analysis in test validation research. Journal of Consulting and Clinical Psychology, 55, 584-594.

FARRELL, W. (1996). Training and professional development in the context of counselling psychology. In R. Woolfe, \& W. Dryden (Eds.), Handbook of counselling psychology. pp. 581- 604. London: Sage.

FRIEDLANDER, M. L., KELLER, K. E., PECA-BAKER, T. A., \& OLK, M. E. (1986). Effects of role conflict on counselor-trainees' self-statements, anxiety level, and performance. Journal of Counseling Psychology, 33, 73-77.

GYSBERS, N.C. (2000). Implementing a whole school approach to guidance through a comprehensive guidance program. Asian Journal of Counselling, 7(2) , 5-17.

GYSBERS, N.C., \& HENDERSON, P. (2000). Developing and managing your school guidance program. Alexandria, VA: American Counseling Association.

HO, D. Y. F. (1996). Filial piety and its psychological consequences. In M. H. Bond (Ed.), The handbook of Chinese psychology (pp. 155-165). Hong Kong: Oxford University Press.

HONG KONG EDUCATION DEPARTMENT (1986) . Guidance work in secondary schools: A suggested guideline for principals and teachers. Hong Kong Government Printer. 
HONG KONG EDUCATION DEPARTMENT (1995). Guidelines on whole school approach to guidance, part 2. Hong Kong Education Department Services Division.

HONG KONG EDUCATION DEPARTMENT (2000). Training courses for guidance teachers in secondary schools (circular memorandum no. 432/2000, 29 August 2000). Hong Kong Education Department.

HONG KONG EDUCATION DEPARTMENT (2001). Guidance work in secondary schools. Hong Kong: Hong Kong Special Administration Region Government.

HORNBY, G. (2003). A model fro counseling in schools. In G. Hornby, C. Hall, \& E. Hall (Eds.), Counselling pupils in schools: Skills and strategies for teachers (pp. 12-22). London: RoutledgeFalmer.

HUI, E. K. P. (1994). Teaching in Hong Kong: Guidance and counselling. Hong Kong: Longman.

HUI, E.K. P. (2000). Guidance as a whole school approach in Hong Kong: From remediation to student development. International Journal for the Advancement of Counselling, 22, 69-82.

JOHNSON, E., BAKER, S. B., KOALA, M., KISELICA, M. S., \& THOMPSON III, E. C. (1989). Counseling self-efficacy and counseling competence in pre-practicum training. Counselor Education and Supervision, 28, 205-218. 
JORESKOG, K. G., \& SORBOM, D. (1985). LISREL VI: An analysis of linear structural relationships by the method of maximum likelihood. Mooresville, IN: Scientific Software.

KLINE, R. B. (1998). Principles and practices of structural equation modeling. New York: Guilford.

KWAN, K. L. K. (2000). Counseling Chinese peoples: Perspectives of filial piety. Asian Journal of Counselling, 7(1), 23-41.

LAIRIO, M., \& NISSILAE, P. (2002). Towards networking in counselling: A follow-up study of Finnish school counselling. British Journal of Guidance and Counselling, 30(2), 159-172.

LARSON, L. M., \& DANIELS, J. A. (1998). Review of the counseling self-efficacy literature. The Counseling Psychologist, 26(2), 179-218.

LARSON, L. M., SUZUKI, L.A., GILLESPIE, K.N., POTENZA, M.T., BECHTEL, M.A., \& TOULOUSE, A. (1992). Development and validation of the counseling self-estimate inventory. Journal of Counseling Psychology, 39, 105-120.

LAU, P. S. Y. (2000). Practising counselling in Chinese communities: Some reflections on cultural competence and indigenization. Asian Journal of Counselling, 7(1), 43-52.

LENT, R.W., HACKETT, G., \& BROWN, S.D. (1998). Extending social cognitive 
theory to counselor training: problems and prospects. The Counseling Psychologist, 26, 296-306.

LENT, R.W., HILL, C.E., \& HOFFMAN, M.A. (2003). Development and validation of the counselor activity self-efficacy scales. Journal of Counseling Psychology, 50, 1, 97-108.

LUK FONG, Y. Y. P., \& LUNG, C. L. (1999). Guidance and counseling services in Hong Kong secondary schools: Profiles and possibilities. Hong Kong: Hong Kong Institute of Education.

MACCALLUM, R.C., BROWNE, M., \& SUGAWARA, H. (1996). Power analysis and determination of sample size for covariance structure modeling. Psychological Methods,1, 130-149.

MARGOLIES, R., WACHTEL, A. B., \& SCHMELKIN, L. P. (1986). Perceived self-efficacy in psychiatry. Journal of Psychiatric Education, 10, 120-128.

MELCHERT, T. P., HAYS, V. L., WILJANEN, L. M., \& KOLOCEK, A. K. (1996). Testing models of counselor development with a measure of counseling self-efficacy. Journal of Counseling \& Development, 74, 640-644.

MILLER, J., MANTHEI, R., \& Gilmore, A. (1993). School counsellors and guidance network: roles revisited. New Zealand Journal of Educational Studies, 28 (2): 105-124. 
MUNSON, W. W., ZOERINK, D. A., \& STADULIS, R. E. (1986). Training potential therapeutic recreators for self-efficacy and competence in interpersonal skills. Therapeutic Recreation Journal, 20, 53-62.

O’BRIEN, K. M., HEPPNER, M. J., FLORES, L. Y., \& BIKOS, L. H. (1997). The career counseling self-efficacy scale: Instrument development and training applications. Journal of Counseling Psychology, 44, 20-31.

PATTERSON, C. H. (1996). Multicultural counseling: From diversity to universality. Journal of Counseling \& Development, 74, 227-231.

PEDERSEN, P. (1996). The importance of both similarities and differences in multicultural counseling: Reaction to C. H. Patterson. Journal of Counseling \& Development, 74, 236-237.

QUINTANA, S.M., \& MAXWELL, S.E. (1999). Implications of recent developments in structural equation modeling for counseling psychology. Counseling Psychologist, 27 (4), 485-527.

SCHMIDT, J..J. (1997). Invitational counselling: An expanded framework for comprehensive school counselling programs. Canadian Journal of Counselling, 3(1), 6-17.

SHARPLEY, C. F., \& RIDGWAY, I. R. (1993). An evaluation of the effectiveness of 
self-efficacy as a predictor of trainee’s counselling skills performance. British Journal of Guidance and Counselling, 21, 73-81.

SHEK, D. T. L. 1993. Factor structure of the Chinese version of the general health questionnaire (GHQ-30): A confirmatory factor analysis. Journal of Clinical Psychology, 49(5), 678-684.

SHEK, D. T. L. (1999). The development of counselling in four Asian communities: A critical review of the review papers. Asian Journal of Counselling, 6(2), 97-114.

SHILLITO-CLARKE, C. (1996). Ethical issues in counselling psychology. R.

Woolfe, \& W. Dryden (Eds.), Handbook of counselling psychology ( pp. 555-580). London: Sage.

SIPPS, G.J., SUGDEN, G.J., \& FAIVER, C.M. (1988). Counselor training level and verbal response type: Their relationship to efficacy and outcome expectations. Journal of Counseling Psychology, 35, 397-401.

STEIGER, J.H., \& LIND, J.C. (1980, June). Statistically based tests for the number of common factors. Paper presented at the annual meeting of the Psychometric Society, Iowa City, IA.

SUTTON Jr., J. N., \& FALL, M. (1995). The relationship of school climate factors to counselor self-efficacy. Journal of Counseling and Development, 73, 331-336.

WATKINS, D. (1989). The role of confirmatory factor analysis in cross-cultural research. International Journal of Psychology, 24, 685-701. 
WATKINS, C. (2001). Comprehensive guidance programs in an international context. Professional School Counseling, 4(4), 262-271.

WHEATON, B. (1987). Assessment of fit over-identified models with latent variables. Sociological Methods and Research, 16, 118-154.

YUEN, M. (in press). Exploring Hong Kong Chinese guidance teachers’ positive beliefs: A focus group study. International Journal for the Advancement of Counselling

YUEN, M.T., LAU, P. S.Y., \& CHAN, R. M. C. (2000). Improving school guidance programs: A conversation with Norman C. Gysbers. Asian Journal of Counselling, $7(2), 19-41$

YUEN, M., LAM, M.P., \& SHEK, D.T.L. (2001, June). Involvement and training needs in counseling and guidance among guidance teachers in Hong Kong. Paper presented at the Bi-Annual International Conference in Counseling, Hong Kong Professional Counselor Association, Hong Kong.

YUEN, M., LAU, S.Y., SHEK, D. T. L., \& LAM, M. P. (2002). Confirmatory factor analysis and reliability of the Chinese version of the Maslach Burnout Inventory among guidance teachers in Hong Kong. Psychological Reports, 91, 1081-1086.

YUEN, M., SHEK, D.T.L., LAM M.P. , LAU, P.S.Y., \& CHAN, R. M.C. (2003). Confirmatory factor analysis and reliability of the Chinese version of a revised 
teacher efficacy scale among guidance teachers in Hong Kong. Psychologia, 46, $67-78$.

YUEN, M., \& WESTWOOD, P. (2001). Integrating students with special needs in Hong Kong secondary schools: Teachers' attitudes and their possible relationship to guidance training. International Journal of Special Education, 16(2), 69-84.

YUEN, M., \& WESTWOOD, P. (2002). Teachers' attitudes toward integration: Validation of a Chinese version of the attitudes toward mainstreaming scale (ATMS). Psychologia, 45. 1-11. 
TABLE I. Demographics, Guidance Training, and Guidance Status

\begin{tabular}{|c|c|c|}
\hline \multirow[b]{2}{*}{ Demographic } & \multicolumn{2}{|c|}{$\begin{array}{l}\text { Guidance teachers } \\
\qquad(\mathrm{N}=578)\end{array}$} \\
\hline & $n$ & $\%$ \\
\hline \multicolumn{3}{|l|}{ Gender } \\
\hline Male & 167 & 28.9 \\
\hline Female & 396 & 68.5 \\
\hline No Response & 15 & 2.6 \\
\hline \multicolumn{3}{|l|}{ Age } \\
\hline $20-29$ & 84 & 14.5 \\
\hline $30-39$ & 274 & 47.4 \\
\hline $40-49$ & 170 & 29.4 \\
\hline 50 or above & 34 & 5.9 \\
\hline No response & 16 & 2.8 \\
\hline \multicolumn{3}{|l|}{ Guidance Training } \\
\hline No & 66 & 11.4 \\
\hline About 15-60 hr. & 141 & 24.4 \\
\hline Certificate course & 277 & 47.9 \\
\hline Master degree & 35 & 6.1 \\
\hline Others & 50 & 8.7 \\
\hline No response & 9 & 1.6 \\
\hline \multicolumn{3}{|l|}{ Guidance Status } \\
\hline Guidance team leader & 315 & 54.5 \\
\hline Guidance team member & 263 & 45.5 \\
\hline
\end{tabular}


TABLE II. Summary Confirmatory Factor Analytic Results related to the 37-Item

Five-Factor Structure of the C-COSE

\begin{tabular}{|c|c|c|c|c|c|c|c|c|}
\hline \multirow[b]{2}{*}{ Model specification } & \multicolumn{8}{|c|}{ Goodness-of-fit indices } \\
\hline & $\mathrm{X}^{2}$ & $\mathrm{X}^{2} /$ d.f. & NNFI & CFI & GFI & AGFI & RMSR & RMSEA \\
\hline \multicolumn{9}{|l|}{ Total sample $(\mathrm{N}=578)$} \\
\hline Model 1 & $3748.695^{*}$ & 5.960 & .655 & .674 & .521 & .464 & .090 & .098 \\
\hline Model 2 & $2125.228^{*}$ & 3.433 & .831 & .843 & .785 & .756 & .073 & .068 \\
\hline Model 3 & 10245.366* & 15.383 & .000 & .000 & .188 & .142 & .258 & .166 \\
\hline \multicolumn{9}{|l|}{ Sub-sample 1(n=66) } \\
\hline \multicolumn{9}{|l|}{ (Guidance teachers with } \\
\hline \multicolumn{9}{|l|}{ no training) } \\
\hline Model 1 & $1291.357^{*}$ & 2.053 & .477 & .506 & .428 & .361 & .095 & .136 \\
\hline Model 2 & $1105.181^{*}$ & 1.785 & .610 & 638 & .552 & .491 & .085 & .118 \\
\hline Model 3 & $2007.741^{*}$ & 3.015 & .000 & .000 & .194 & .150 & .206 & .187 \\
\hline \multicolumn{9}{|l|}{ Sub-sample $2(n=141)$} \\
\hline \multicolumn{9}{|l|}{ (Guidance teachers with } \\
\hline \multicolumn{9}{|l|}{ 15- $60 \mathrm{hr}$ training) } \\
\hline Model 1 & $1702.638^{*}$ & 2.707 & .411 & .444 & .418 & .350 & .115 & .117 \\
\hline Model 2 & $1192.195^{*}$ & 1.926 & .681 & .703 & .676 & .632 & .091 & .086 \\
\hline Model 3 & 2596.901 & 3.899 & .000 & .000 & .276 & .236 & .182 & .153 \\
\hline \multicolumn{9}{|l|}{ Sub-sample $3(n=312)$} \\
\hline \multicolumn{9}{|l|}{ (Guidance teachers with } \\
\hline \multicolumn{9}{|l|}{ certificate/master level } \\
\hline \multicolumn{9}{|l|}{ training) } \\
\hline Model 1 & 2293.528 & 3.646 & .674 & 692 & .525 & .469 & .086 & .096 \\
\hline Model 2 & 1445.530 & 2.335 & .835 & .847 & .754 & .720 & .076 & .068 \\
\hline Model 3 & 6069.043 & 9.113 & .000 & .000 & .178 & .132 & .273 & .168 \\
\hline
\end{tabular}

Note. Model 1: General counseling self-efficacy; Model 2: Five primary factors; Model 3: Null model;

$\mathrm{X}^{2}=$ Chi-square value; $\mathrm{X}^{2} / \mathrm{df}=$ Chi square / degrees-of-freedom ratio; GFI = Goodness-of-fit index;

AGFI = Adjusted goodness-of-fit index; RMSR = Root mean square residual;

NNFI = Bentler-Bonett nonnormal fit lndex; CFI = Comparative fit index;

RMSEA = Root mean square error of approximation;

${ }^{*} \mathrm{p}<.001$ 
TABLE III. Means, SDs, Corrected Item Total Correlations and Factor Loadings for Items of the C-COSE Among the Total Sample and Sub-Sample 3 (Model 2)

\begin{tabular}{|c|c|c|c|c|c|c|}
\hline \multirow[t]{2}{*}{ Factors and item contents } & $\begin{array}{l}\text { Total } \\
\text { Sample }\end{array}$ & $\begin{array}{l}\text { Sub- } \\
\text { Sample } \\
3\end{array}$ & $\begin{array}{l}\text { Total } \\
\text { Sample }\end{array}$ & $\begin{array}{l}\text { Sub- } \\
\text { Sample } \\
3\end{array}$ & $\begin{array}{c}\text { Total } \\
\text { Sample } \\
(\mathrm{N}=578)\end{array}$ & $\begin{array}{l}\text { Sub- } \\
\text { Sample } \\
3 \\
(n=312)\end{array}$ \\
\hline & $\begin{array}{l}\text { Mean } \\
\text { (SD) }\end{array}$ & $\begin{array}{l}\text { Mean } \\
(\mathrm{SD})\end{array}$ & CITC & CITC & $\begin{array}{l}\text { Factor } \\
\text { loading }\end{array}$ & $\begin{array}{l}\text { Factor } \\
\text { loading }\end{array}$ \\
\hline \multicolumn{7}{|l|}{ Factor 1 Microskills } \\
\hline 1. respond concisely & $\begin{array}{l}4.60 \\
(.68)\end{array}$ & $\begin{array}{l}4.72 \\
(.61)\end{array}$ & .59 & .72 & .74 & .77 \\
\hline 3. end a session & $\begin{array}{l}4.62 \\
(.71)\end{array}$ & $\begin{array}{l}4.76 \\
(.68)\end{array}$ & .54 & .60 & .69 & .66 \\
\hline 4. respond appropriately & $\begin{array}{l}4.50 \\
(.73)\end{array}$ & $\begin{array}{l}4.57 \\
(.75)\end{array}$ & .57 & .73 & .75 & .78 \\
\hline 5. interpret concisely & $\begin{array}{l}4.49 \\
(.70)\end{array}$ & $\begin{array}{l}4.57 \\
(.69)\end{array}$ & .59 & .77 & .78 & .81 \\
\hline $\begin{array}{l}\text { 8. respond in appropriate length of } \\
\text { time }\end{array}$ & $\begin{array}{l}4.75 \\
(.61)\end{array}$ & $\begin{array}{l}4.8 \\
(.64)\end{array}$ & .53 & .58 & .70 & .71 \\
\hline 10. respond consistently & $\begin{array}{l}4.56 \\
(.73)\end{array}$ & $\begin{array}{l}4.66 \\
(.70)\end{array}$ & .51 & .66 & .69 & .69 \\
\hline 11. earn respect from client & $\begin{array}{l}4.80 \\
(.68)\end{array}$ & $\begin{array}{l}4.90 \\
(.65)\end{array}$ & .56 & .64 & .69 & .66 \\
\hline 12. confront effectively & $\begin{array}{l}4.53 \\
(.69)\end{array}$ & $\begin{array}{l}4.65 \\
(.70)\end{array}$ & .62 & .66 & .75 & .70 \\
\hline 14. interpret consistently & $\begin{array}{l}4.67 \\
(.63)\end{array}$ & $\begin{array}{l}4.79 \\
(.59)\end{array}$ & .55 & .71 & .77 & .75 \\
\hline 17. use clear wording & $\begin{array}{l}4.63 \\
(.64)\end{array}$ & $\begin{array}{l}4.74 \\
(.61)\end{array}$ & .60 & .71 & .76 & .74 \\
\hline 32. conceptualize client's problem & $\begin{array}{l}4.47 \\
(.75)\end{array}$ & $\begin{array}{l}4.63 \\
(.72)\end{array}$ & .58 & .64 & .68 & .67 \\
\hline 34. assess readiness to change & $\begin{array}{l}4.37 \\
(.71)\end{array}$ & $\begin{array}{l}4.53 \\
(.70)\end{array}$ & .54 & .56 & .58 & .60 \\
\hline \multicolumn{7}{|l|}{ Factor 2 Process } \\
\hline 6. confusing responses* & $\begin{array}{l}4.01 \\
(1.00)\end{array}$ & $\begin{array}{l}4.11 \\
(1.03)\end{array}$ & .54 & .64 & .60 & .63 \\
\hline 9. not appropriate response* & $\begin{array}{l}3.64 \\
(1.01)\end{array}$ & $\begin{array}{l}3.75 \\
(1.07)\end{array}$ & .52 & .60 & .60 & .62 \\
\hline 16. not maintain energy level* & $\begin{array}{l}3.92 \\
(1.12)\end{array}$ & $\begin{array}{l}4.02 \\
(1.15)\end{array}$ & .48 & .61 & .59 & .60 \\
\hline 18. not natural* & $\begin{array}{l}3.83 \\
(1.08)\end{array}$ & $\begin{array}{l}3.99 \\
(1.11)\end{array}$ & .53 & .64 & .65 & .63 \\
\hline $\begin{array}{l}\text { 19. not understand nonverbal } \\
\text { behaviors* }\end{array}$ & $\begin{array}{l}3.81 \\
(1.00)\end{array}$ & $\begin{array}{l}3.93 \\
(1.02)\end{array}$ & .69 & .76 & .79 & .81 \\
\hline $\begin{array}{l}\text { 21. not accurate assessment of } \\
\text { problem* }\end{array}$ & $\begin{array}{l}3.50 \\
(.98)\end{array}$ & $\begin{array}{l}3.64 \\
(1.03)\end{array}$ & .63 & .67 & .72 & .72 \\
\hline 22. uncertain about confrontation* & $\begin{array}{l}3.64 \\
(.97)\end{array}$ & $\begin{array}{l}3.76 \\
(1.01)\end{array}$ & .70 & .73 & .81 & .81 \\
\hline 23. not effective responses* & $\begin{array}{l}3.87 \\
(.93)\end{array}$ & $\begin{array}{l}3.99 \\
(.95)\end{array}$ & .71 & .78 & .83 & .84 \\
\hline 31.not useful in clarifying problem* & $\begin{array}{l}3.72 \\
(.97)\end{array}$ & $\begin{array}{l}3.91 \\
(.98)\end{array}$ & .63 & .67 & .69 & .73 \\
\hline
\end{tabular}


33. unsure about goals*

$\begin{array}{ll}4.01 & 4.14 \\ (.93) & (.92)\end{array}$

.68

.73

.73

Factor 3 Difficult Client Behavior

15. enough fundamental knowledge

4.46
$(.87)$

$4.67 \quad .62$

$.55 \quad .70$

.67

20. probes

4.31

(.75)

(.80)

4.43

.61

$.59 \quad .68$

.68

24. not enough techniques for

3.63

(.78) problems*

(1.18)

3.85

.67

$.61 \quad .74$

.72

3.64

(1.19)

25. crisis situations

(1.03)

3.79

.48

$.47 \quad .58$

.57

26. uncomfortable with unmotivated

3.22

(1.01) client*

(.96)

3.22

.36

$.41 \quad .36$

.42

27. nonverbal client*

2.98

(.98)

3.07

.45

$.57 \quad .49$

.61

(.95)

(1.00)

28. indecisive client*

3.45

.62

$.68 \quad .64$

.74

Factor 4 Cultural Competence

(.97) (1.00)

29. bridge cultural differences

$\begin{array}{llllll}4.14 & 4.22 & .39 & .46 & .57 & .55\end{array}$

(.86) $\quad(.88)$

$4.11 \quad 4.22$

$(.90)$

(.92)

.60

$.43 \quad .79$

.82

36. different cultural perspective*

$3.71 \quad 3.82$

(.98) $\quad(.99)$

37. lower socioeconomic status*

4.56

4.69

.45

$.45 \quad .39$

.40

(.95)

(.93)

Factor 5 Awareness of Values

2. impose values*

2.85
$(.88)$
3.77

2.89

.41

$.31 \quad .34$

.32

7. not respect client's values*

3.77

(.90)

.08

$.14 \quad .00$

.04

(1.11)

3.87

.10

$.14 \quad .28$

.24

4.59

(1.12)

13. resolve conflicts in personal life

(.74)

4.69

$-.06$

$-.11 \quad .56$

.58

2.23

$(.72)$

35. give advice*

(.65)

$2.15 \quad-.11 \quad-.07 \quad .48$

.48

Note. Items were adapted and translated from the Counselling Self-Estimate Inventory (COSE) devised by Larson et al. (1992).

*Items that were reverse coded. CITC= Corrected Item Total Correlations 
TABLE IV. Sub-scale Correlations and Summary Statistics for the C-COSE

Based on Model $2(\mathrm{~N}=556)$

\begin{tabular}{|c|c|c|c|c|c|c|c|}
\hline & Sub-scales & 1 & 2 & 3 & 4 & $\begin{array}{c}\text { Coefficient } \\
\text { Alpha }\end{array}$ & $\begin{array}{c}\text { Item Means } \\
\text { Mean } \\
\text { (Subscale S.D.) }\end{array}$ \\
\hline 1. & Microskills & - & & & & .92 & $\begin{array}{c}4.58 \\
(6.09)\end{array}$ \\
\hline 2. & Process & $.50^{*}$ & - & & & .91 & $\begin{array}{c}3.80 \\
(7.39)\end{array}$ \\
\hline 3. & Difficult Client Behaviour & $.62 *$ & $.67^{*}$ & - & & .80 & $\begin{array}{c}3.65 \\
(4.59)\end{array}$ \\
\hline 4. & Cultural Competence & $.55^{*}$ & $.56^{*}$ & $.57^{*}$ & - & .62 & $\begin{array}{c}4.13 \\
(2.55)\end{array}$ \\
\hline 5. & Awareness of Values & $.16^{*}$ & $.40^{*}$ & $.29 *$ & $.21^{*}$ & .14 & $\begin{array}{c}3.36 \\
(1.74)\end{array}$ \\
\hline
\end{tabular}

Note: For the total scale, the alpha is .94 , item means mean $=4.01$, scale mean $=148.45$, and scale S.D.=

17.86. ${ }^{*} \mathrm{p}<.01$ (2-tailed) 
TABLE V. Comparison of Alternative Factor Models on the C-COSE with Items 2, 7, 13, and 35 Deleted from the Scale

\begin{tabular}{|c|c|c|c|c|c|c|c|c|}
\hline \multirow[b]{2}{*}{ Model specification } & \multicolumn{8}{|c|}{ Goodness-of-fit indices } \\
\hline & $\mathrm{X}^{2}$ & $\mathrm{X}^{2} / \mathrm{df}$ & NNFI & CFI & GFI & AGFI & RMSR & RMSEA \\
\hline \multicolumn{9}{|c|}{ Whole sample $(\mathrm{N}=578)$} \\
\hline \multicolumn{9}{|c|}{ Model 4: One general factor, items 2, 7, 13, \& 35 deleted } \\
\hline & $3398.644 *$ & 6.866 & .659 & .681 & .524 & .461 & .090 & .105 \\
\hline \multicolumn{9}{|c|}{ Model 5: Four primary factors, items 2, 7, 13, \& 35 deleted } \\
\hline & 8565.599* & 3.636 & .847 & .858 & .804 & .776 & .067 & .070 \\
\hline \multicolumn{9}{|c|}{ Model 6: Null model, items 2,7, 13, \& 35 deleted } \\
\hline & $9621.599 *$ & 18.222 & .000 & .000 & .189 & .138 & .275 & .180 \\
\hline \multicolumn{9}{|c|}{ Sub-sample1 (Guidance Teachers without training; $n=66$ )) } \\
\hline \multicolumn{9}{|c|}{ Model 4: One general factor, items 2, 7, 13, \& 35 deleted } \\
\hline & $1074.622 *$ & 2.171 & .484 & .516 & .439 & .364 & .099 & .142 \\
\hline \multicolumn{9}{|c|}{ Model 5: Four primary factors, items 2, 7, 13, \& 35 deleted } \\
\hline & $899.465 *$ & 1.839 & .630 & .657 & .572 & .509 & .087 & .120 \\
\hline \multicolumn{9}{|c|}{ Model 6: Null model, items 2, 7, 13, 35 deleted } \\
\hline & $1725.663 *$ & 3.268 & .000 & .000 & .208 & .159 & .213 & .197 \\
\hline \multicolumn{9}{|c|}{ Sub-sample 2 (Guidance Teachers with 15 to 60 hours training; $n=141$ ) } \\
\hline \multicolumn{9}{|c|}{ Model 4: One general factor, items 2, 7, 13, \& 35 deleted } \\
\hline & $1417.327 *$ & 2.863 & .447 & .482 & .431 & .356 & .088 & .120 \\
\hline \multicolumn{9}{|c|}{ Model 5: Four primary factors, items 2, 7, 13, \& 35 deleted } \\
\hline & $922.361 *$ & 1.886 & .737 & .756 & .707 & .664 & .084 & .083 \\
\hline \multicolumn{9}{|c|}{ Model 6: Null model, items 2, 7, 13, 35 deleted } \\
\hline & $2307.272 *$ & 4.370 & .000 & .000 & .276 & .231 & .195 & .162 \\
\hline
\end{tabular}

Sub-sample3 (Guidance Teachers with certificate/master level training;

$n=312)$

Model 4: One general factor, items 2, 7, 13, \& 35 deleted

$\begin{array}{lllllllll}202.735 * & 4.082 & .683 & .703 & .541 & .480 & .083 & .03\end{array}$

Model 5: Four primary factors, items 2, 7, 13, \& 35 deleted

$\begin{array}{lllllllll}1195.310 * & 2.444 & .851 & .862 & .775 & .742 & .065 & .071\end{array}$

Model 6: Null model, items 2, 7, 13, 35 deleted

5661.493* $\quad 10.722 \quad .000 \quad .000$

Note: $\mathrm{X}^{2}=$ Chi-square value; $\mathrm{X}^{2} / \mathrm{df}=$ Chi square / degrees-of-freedom ratio; GFI = Goodness-of-fit index; AGFI = Adjusted goodness-of-fit index; RMSR = Root mean square residual; NNFI = Bentler-Bonett nonnormal fit lndex; CFI = Comparative fit index; RMSEA = Root mean square error of approximation; $* \mathrm{p}<.001$ 
Table VI.Factor Item Loadings for the C-COSE (Model 5) among Total Sample and Sub-Samples

\begin{tabular}{|c|c|c|c|c|}
\hline Item no. & $\begin{array}{c}\text { Total sample } \\
(\mathrm{N}=578)\end{array}$ & $\begin{array}{c}\text { Sub-sample } 1 \\
(n=66)\end{array}$ & $\begin{array}{c}\text { Sub-sample } 2 \\
(n=141)\end{array}$ & $\begin{array}{c}\text { Sub-sample } 3 \\
(n=312)\end{array}$ \\
\hline \multicolumn{5}{|l|}{ Factor 1} \\
\hline 1 & .74 & .77 & .58 & .77 \\
\hline 3 & .68 & .78 & .62 & .65 \\
\hline 4 & .75 & .76 & .68 & .78 \\
\hline 5 & .79 & .85 & .65 & .81 \\
\hline 8 & .64 & .77 & .56 & .60 \\
\hline 10 & .69 & .81 & .66 & .69 \\
\hline 11 & .68 & .72 & .65 & .66 \\
\hline 12 & .75 & .76 & .74 & .71 \\
\hline 14 & .77 & .80 & .73 & .74 \\
\hline 17 & .76 & .82 & .64 & .74 \\
\hline 32 & .68 & .60 & .65 & .68 \\
\hline 34 & .58 & .57 & .38 & .60 \\
\hline \multicolumn{5}{|l|}{ Factor 2} \\
\hline 6 & .60 & .46 & .63 & .64 \\
\hline 9 & .60 & .29 & .65 & .62 \\
\hline 16 & .59 & .25 & .71 & .60 \\
\hline 18 & .65 & .51 & .67 & .64 \\
\hline 19 & .79 & .64 & .70 & .81 \\
\hline 21 & .73 & .73 & .69 & .72 \\
\hline 22 & .81 & .76 & .77 & .81 \\
\hline 23 & .83 & .80 & .76 & .84 \\
\hline 31 & .70 & .52 & .57 & .73 \\
\hline 33 & .74 & .76 & .67 & .74 \\
\hline \multicolumn{5}{|l|}{ Factor 3} \\
\hline 15 & .70 & .73 & .28 & .68 \\
\hline 20 & .69 & .56 & .29 & .69 \\
\hline 24 & .74 & .90 & .70 & .72 \\
\hline 25 & .58 & .64 & .19 & .57 \\
\hline 26 & .36 & .30 & .62 & .40 \\
\hline 27 & .49 & .27 & .69 & .59 \\
\hline 28 & .64 & .45 & .76 & .71 \\
\hline \multicolumn{5}{|l|}{ Factor 4} \\
\hline 29 & .55 & .64 & .61 & .55 \\
\hline 30 & .80 & .73 & .81 & .83 \\
\hline 36 & .39 & .34 & .15 & .39 \\
\hline 37 & .33 & .16 & .25 & .31 \\
\hline
\end{tabular}

Note. Factor 1: Microskills; Factor 2: Process ; Factor 3: Difficult Client Behaviour; Factor 4: Cultural Competencies; Sub-sample 1, guidance teachers with no training in counseling; Sub-sample 2, guidance teachers with 15- 60 hours of training in counseling; Sub-sample 3, guidance teachers with certificate or master level training. 
TABLE VII. Subscale Intercorrelations and Summary Statistics for the Four Subscales of the C-COSE Based on Model 5 among the Sub-Samples

\begin{tabular}{|c|c|c|c|c|c|c|}
\hline & Subscales & 1 & 2 & 3 & $\begin{array}{l}\text { Coefficient } \\
\text { Alpha }\end{array}$ & $\begin{array}{c}\text { Item Means } \\
\text { Mean } \\
\text { (Sub-scale S.D.) }\end{array}$ \\
\hline & Sub-sample 1(n=62) & & & & & \\
\hline 1 & Microskills & - & & & .94 & $\begin{array}{c}4.24 \\
(6.60)\end{array}$ \\
\hline 2. & Process & $.38 *$ & - & & .82 & $\begin{array}{c}3.49 \\
(5.25)\end{array}$ \\
\hline 3. & Difficult Client Behaviour & $.43 *$ & $.54^{*}$ & - & .76 & $\begin{array}{c}3.24 \\
(3.91)\end{array}$ \\
\hline 4. & Cultural Competence & $.56^{*}$ & $.58 *$ & $.46^{*}$ & .57 & $\begin{array}{c}3.82 \\
(2.28)\end{array}$ \\
\hline
\end{tabular}

Sub-sample $2(n=135)$

\begin{tabular}{|c|c|c|c|c|c|c|}
\hline 1. & Microskills & - & & & .89 & $\begin{array}{c}4.48 \\
(5.09)\end{array}$ \\
\hline 2. & Process & $.23 *$ & - & & .90 & $\begin{array}{c}3.61 \\
(6.63)\end{array}$ \\
\hline 3. & Difficult Client Behaviour & $.41^{*}$ & $.57 *$ & - & .74 & $\begin{array}{c}3.53 \\
(3.91)\end{array}$ \\
\hline 4. & Cultural Competence & $.35 *$ & $.49 *$ & $.41 *$ & .56 & $\begin{array}{c}4.01 \\
(2.32)\end{array}$ \\
\hline
\end{tabular}

Sub-sample $3(n=305)$

1. Microskills

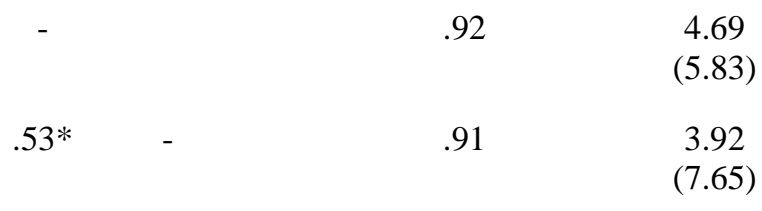

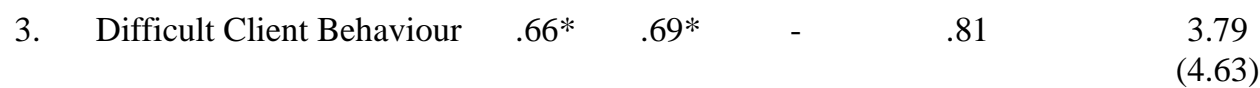

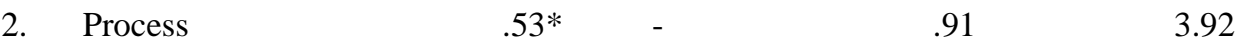

$\begin{array}{llllll}\text { 4. Cultural Competence } & .57 * & .53 * & .60 * & .63 & 4.24\end{array}$

(2.57)

Note. Sub-sample 1, guidance teachers with no training in counseling; Sub-sample 2, guidance teachers with 15- 60 hours of training in counseling; Sub-sample 3, guidance teachers with certificate or master level training.

${ }^{*} \mathrm{p}<.01$ (2-tailed). 